\section{More Than Just Apes}

\section{S. Joshua Swamidass (D)}

https://doi.org/10.54739/xwcu

Scientifically speaking, humans appear to be genetically-modified apes, with genomes that are more than $98 \%$ similar to chimpanzees in coding regions, and about $95 \%$ similar overall. ${ }^{1}$ We are 10 times closer to apes than mice are to rats. As I have previously explained, this is evidence for the common descent of man. Even if common descent is ultimately false (as some religious leaders might reasonably believe), somehow this evidence exists. Now, starting from this striking genetic similarity, some argue that humans are just animals, unexceptional in every way.

This brings us to our question: we are formed from the dust of the earth, but are we just dust? Humans are intelligent, geneticallymodified apes, but are we just apes?

Commonly, scientists say "we are just intelligent animals." $\underline{A}$ charming article in the New York Times by the scientist Frans de Waal is emblematic. His article starts with stories about tickling apes, declaring: "Humans: Not So Special." Dr. de Waal correctly argues humans and are much more similar to animals than we usually think, and then explains:

Science nowadays often starts by assuming continuity between humans and animals, while shifting the burden of proof to those who insist on differences.

Scientists focus on the continuity between humans and animals. Right now, surprising similarities between humans and animals are expected. This expectation motivates scientists to treat apes like humans, bringing us both Koko the sign language gorilla and the abusive and tragic episode of Nim Chimpsky. ${ }^{2}$ Those that insist on differences, however, need to fervently make their case, and might even be suspected of religious delusion.

Nim Chimpsky is a chimpanzee that was raised by researchers like a human child, in the hope that a proper upbringing might encourage more human traits to emerge. The experiment failed horribly with tragic and scaring results for everyone involved, including $\mathrm{Nim}$. The documentary Project Nim tells this sad story.

Is this really what science tells us? That humans are just intelligent apes, unexceptional in most important ways? Many scientists answer, "yes, we are just apes."

1. The $98 \%$ figure is the similarity in coding regions. Obviously measuring in other ways produces different numbers. No matter how we look at it, humans are genetically very similar to apes, much more similar than mice are to rats.

2. Nim is the Chimpanzee pictured in the feature image, who was raised as a human child, with tragic consequences for all involved.

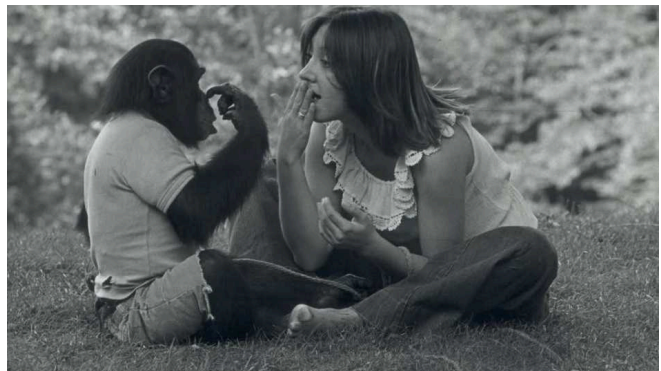

Even non-religious people reject evolution because of this answer. Any theory that argues "humans are just animals" seems dehumanizing, and might even be dangerous. On face value, this feels wrong. This, however, is the instinct and the message of many in the current scientific world.

So what is the truth? Of course, scientifically speaking, we are genetically modified apes, $98 \%$ to $95 \%$ similar to them. Remarkably, a mere $2 \%$ to $5 \%$ difference in our genomes, biologically-speaking, is more than enough to explain the "human condition." However, it is fallacious to argue from genetic similarity, that we are not exceptional. In fact, this leap misrepresents our current understanding of evolution. According to neutral theory, genome similarity measures the time since we separated from apes (which was quite recently), rather than meaningfully measuring functional differences or distance. ${ }^{4}$

Therefore, we should consider the obvious. Even if we are similar to apes, as Dr. Ajit Varki puts it, “humans are very [very] unusual." We humans, it seems, are more than just apes.

This last April, I had the privilege of presenting with Varki at UC San Diego in front of a crowd of hundreds of some of the smartest students on earth. A brilliant scientist, Varki is a leading thinker on human evolution. He runs CARTA, an interdisciplinary center for studying human evolution at UC San Diego, and wrote Denial, a

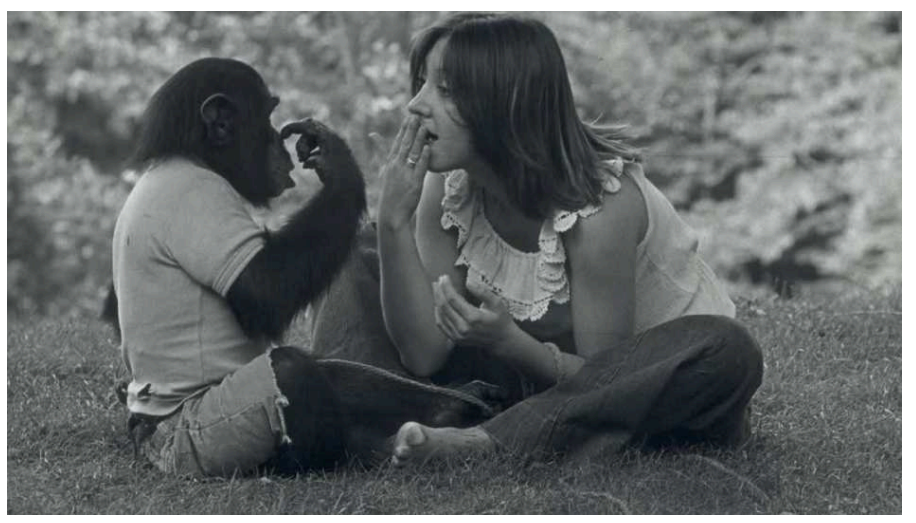

3. This is based on our current understanding of biology, supported by data. Still science is provisional, and this is certainly a surprising claim. It helps to remember that very small changes in our genome can cause very large changes in our person. Unfortunately, a full discussion of this is beyond the scope of this article. Curious readers may click the links in the sentence for more information.

4. This is why, for example, rats and mice are 10 times more different than humans are from chimpanzees, the diverged from one another before humans and apes, and their clock ticks faster too. 
book explaining his understanding of the "singularity" in the rise of the human race.

The full conversation is really worth watching. We discuss our religious upbringings, our journeys into science, my approach to seeking peace in the Creation War with common ground and also human exceptionalism. It's this last topic that I wanted outline here, to explain Varki's scientific understanding of exceptionalism in our human origins. He wants to know who we humans are and from where we came. As Varki puts it, "humans are very very unusual." He gives several examples, but I will explain just three.

First (at 6:10), humans are the only known species that has out compete all other sibling species (e.g. Neanderthals and Denisovans) to spread into every habitat across the globe. As far as we know, this has never happened before in the history of the planet. $^{5}$

Second, the human mind is unique, and nothing like it has been encountered in all our planet's history. Varki explains "Wallace's Conundrum." Alfred Russel Wallace was the equal co-discoverer of evolution with Charles Darwin, but grew in doubt ofevolution because of the exceptional nature of the human mind. As Varki puts it (at 8:30), "Humans are very very unusual in our abilities and these abilities were already present 70,000 to 100,000 years ago in Africa."

Varki explains a thought experiment (at 37:16). Imagine taking 1,000 babies soon after that time in Africa, 70,000 years ago when we emerged. Bring them to California today, and give them every opportunity. If you come back fifty years later, you won't be able to find them. They will be just like us. "Actually, the experiment has been done. It is called the University of California." People left Africa 70,000 years ago spread across the planet, acquiring new genetic variation as they went, but still have the same remarkable abilities. "That means that all the mental abilities to do calculus, astrophysics, symphonic music, and philosophy, and theology, and Veritas Forums, was already there." This is not a normal example of exaptation (reuse of a structure for a new purpose). How can evolution do that?

The same experiment has been also attempted with chimpanzees too, like Nim Chimpsky and Washoe. Needless to say, the results were different, sometimes even tragic. Chimpanzees are not humans.

Varki is not arguing against evolution. He endorses evolution as unquestioned "fact." Instead, he expresses a genuine astonishment

5. Varki explains that orcas are the closest parallel, but even this is not quite the same and awe in the remarkable and singular details of human origins. A proper understanding of evolution only makes human exceptionalism more fresh and vivid.

Third, the "dictionary experiment" demonstrates the difference between humans and chimpanzees (at 39:20). Here, he explains a simple experiment of his own invention, making use of his daughter and a dictionary. This experiment also demonstrates the wide gulf between humans and chimpanzees. Sure, there are similarities, but the differences? They cannot be counted. The similarities themselves are notable only because the differences are so numerous, obvious, and defining.

Varki is not arguing that evolution is false. Instead, he emphasizes that an honest look at human evolution, even from a strictly scientific perspective, reveals that humans truly are exceptional. A

"singularity" in our planet's history has occurred. Nothing like us has ever arisen on the planet before. Something beautiful and unique has happened here.

The appropriate response to this account is awe and wonder. No matter how much we learn about the mechanisms of evolution, we should remain awestruck that we are so unique. Varki remarked over dinner, "it is not unreasonable when some wonder if God had a role in our origins." I would agree. ${ }^{6}$

Moreover, when scientists deny the obvious evidence for human exceptionalism, they make evolution much harder for many to understand. It is true, scientifically speaking, we are geneticallymodified apes, but we are more than just apes. We are less than $2 \%{ }^{7}$ different than chimpanzees, but in this few percent is an epic leap that never before has evolution achieved, and never before the earth has seen.

Theologically and scientifically speaking, we are formed from the dust of the earth, but we are more than just dust. We should all be able to agree, we humans are more than just apes.

6. A note to the curious, neither Varki or myself think science can prove God's involvement in our origins. We do not support the Intelligent Design movement. As a theistic evolutionist, however, I personally do believe that God created us through an evolutionary process.

7. Of course by measures other than codon difference, like overall genome similarity, the number is slightly different, about 5\%. I'm just using this number for rhetorical consistency. The point still stands with other metrics.

\section{References}

http://swami.wustl.edu/evidence-and-evolution

http://swami.wustl.edu/call-response-tree

http://www.nytimes.com/2016/04/10/opinion/sunday/what-i-learnedfrom-tickling-apes.html

https://en.wikipedia.org/wiki/Frans_de_Waal

https://en.wikipedia.org/wiki/Koko_(gorilla)

http://www.npr.org/2011/07/20/138467156/project-nim-a-chimpsvery-human-very-sad-life

https://www.youtube.com/watch?v=NRLfC09bFYk

https://en.wikipedia.org/wiki/Nim_Chimpsky http://www.pandasthumb.org/archives/2007/07/haldanes-nondil.html

http://genome.cshlp.org/content/15/12/1746.full

https://en.wikipedia.org/wiki/Neutral_theory_of_molecular_evolution

http://cmm.ucsd.edu/varki

https://carta.anthropogeny.org

https://peacefulscience.org/books/denial/

https://www.youtube.com/watch?v=-_YKH3tAIqw

https://en.wikipedia.org/wiki/Ajit_Varki\#Education_and_biography

https://www.youtube.com/watch?v=-_YKH3tAIqw?t=6m10s 
http://www.ncbi.nlm.nih.gov/pubmed/18046751

https://en.wikipedia.org/wiki/Alfred_Russel_Wallace

https://www.youtube.com/watch?v=-_YKH3tAIqw?t=8m30s

https://www.youtube.com/watch?v=-_YKH3tAIqw?t=37m16s

http://www.veritas.org/location/university-of-california-san-diego
https://en.wikipedia.org/wiki/Exaptation https://en.wikipedia.org/wiki/Washoe_(chimpanzee)

https://www.youtube.com/watch?v=-_YKH3tAIqw?t=39m20s http://biologos.org 